\title{
Um encontro com Hans-Georg Gadamer e com muitas mulheres*
}

\author{
Suely Gomes Costa**
}

O livro em pauta, originalmente tese de doutorado em História (PUC-São Paulo), sob orientação da historiadora Maria Odila Leite da Silva Dias, situa, oportunamente, revisões historiográficas abertas pelos debates contemporâneos sobre o tempo histórico, o discurso e a representação do e sobre o passado, a narrativa e a linguagem do historiador; enfim, sobre tudo aquilo que tem agitado os métodos da história. De especial interesse para a história das mulheres e das relações de gênero, o texto move-se "entre certezas e inquietude", como observa Chartier (2002), quanto às tentativas intelectuais que "colocam no centro de seu método as relações que mantêm os discursos $e$ as práticas sociais". Ao trazer experiências femininas na cultura letrada da Bahia, entre 1870 e 1920, o livro associa a inquietude sobre a produção do conhecimento no âmbito das ciências humanas a certezas sobre a oportunidade de perseverar na crítica aos grandes modelos explicativos, que ainda rondam a produção da história das mulheres. A autora enfrenta, sem temor, os conhecidos desafios do ofício do historiador, por entender que "o passado sempre é o olhar do presente"; para desocultá-lo, apóiase no senso histórico, modo de refinar sua sensibilidade de

\footnotetext{
* Resenha de BARreiros Leite, Márcia Maria da Silva. Entre a tinta e o papel. Memórias de leituras e escritas femininas na Bahia (1870-1920). Salvador, Quarteto, 2005. Recebida para publicação em março de 2009, aceita em maio de 2009.

** Doutora em História, Professora do Programa de Pós-Graduação em Políticas Sociais e de História da Universidade Federal Fluminense, Campus do Gragoatá. suelygom@oi.com.br
}

cadernos pagu (32), janeiro-junho de 2009:389-393. 
Um encontro com Hans-Georg Gadamer e com muitas mulheres

pesquisadora, tomando o passado "a partir do próprio contexto em que ele emerge", como lhe sugere Gadamer (1998:18).

Voltada, em particular, para questões relativas à história das mulheres e aos estudos de gênero, a autora se afasta das construções genéricas, da noção de sujeito universal e, assim, localiza singularidades históricas pouco conhecidas. Isso porque escolhe um método de análise que, tanto é "capaz de pensar a complexidade do problema da consciência histórica, quanto também de desenvolver $e$ instigar um pensamento mais plural, com vista à interpretação de passados múltiplos" (18) - grifo da autora. O livro prova, à farta, o quanto determinados canônes, ainda presentes numa certa história das mulheres, insistem numa presumida "condição feminina", assentada em sistemáticas oposições de homens e mulheres e no forte legado da noção universal e abstrata de patriarcalismo (Piscitelli, 2004; Costa, 2004). Desmonta, pois, imagens correntes sobre mulheres brasileiras de todos os tempos, representadas como figuras esmaecidas $e$ fugidias, submissas, de imprecisos contornos intelectuais, predestinadas a prendas domésticas, a habilidades para "artes menores" e para o trato da intimidade pensada sem qualquer sinal político, ou quando, diante de algumas outras, portadoras de idéias próprias, "pessoas de opinião" ou, transgressoras de certas "regras sociais", as pensa como mitos. Como parte dos mesmos cânones ou reforçando-os, acumulam-se representações em relação ao inexorável poder dos homens sobre as mulheres. Em perspectivas como essas, é comum que veleidades intelectuais femininas sejam vistas como inexoravelmente submetidas a impedimentos ou desencorajamentos postos pelos homens. Ao contrário disso, o livro sugere, nas situações estudadas, relações de cumplicidade de homens e mulheres, que também favorecem uma considerável circulação de livros, periódicos e cartas, redes de bibliotecas privadas e públicas. Tais referências sobre acessos das mulheres à leitura e à vida intelectual ampliam as dimensões políticas do cotidiano familiar e expõem complexidades culturais pouco pensadas; a abordagem desse cotidiano se reconstrói $e$ 
confirma a relevância de pesquisas voltadas para a história regional, recorte espacial que dá visibilidade a configurações singulares da presença de mulheres intelectuais na vida social. Lidando com maestria com uma enorme quantidade de fontes, a autora faz emergir a leitura e a escrita de mulheres intelectuais de Salvador, das cidades do recôncavo e do sertão baiano, e oferece ao seu leitor muito das sensibilidades, matéria plural ainda tão invisível, com que se tecem sociabilidades de cada tempo e lugar.

$\mathrm{Na}$ "Introdução" do livro, a autora faz uma cuidadosa exposição de caminhos percorridos de pesquisa: para as questões historiográficas enfrentadas, releva seu encontro com Gadamer e com mulheres baianas intelectuais, das quais se ocupa. Distingue o perfil dessas mulheres: "senhoras e senhorinhas da elite, educadas $e$ instruídas dentro de modelos de letramento $e$ socialização de códigos de cultura vigentes". Não só: apresentanos mulheres, cujas experiências intelectuais "produziram $e$ registraram uma memória coletiva acerca das relações entre os sexos no contexto em estudo". Cuida bem para afastá-las do risco de serem enquadradas como mitos ou exceções, e as exibe em carne e osso, através de uma infinidade de registros - biografias, memórias, escritos literários, cartas, fotografias e periódicos.

Seguem-se quatro capítulos. A autora os agrupa em duas partes. Na primeira (Capítulo 1 - "História da leitura e leitoras baianas: práticas culturais e perfis femininos"; Capítulo 2 - "Os espaços e as experiências de leitura feminina: a aventura do livro"), os "atos de ler" estão nos espaços da casa, tomados como lugares de sociabilidades intelectuais, nem sempre visíveis nos estudos sobre brasileiras letradas. Além de recorrer às memórias de Anna Ribeiro de Góes Bittencourt, autora de Longos Serões do Campo, numa narrativa familiar, o texto examina escritos literários de cunho autobiográfico de Anna Teófila Autran, desvendando muito das relações da vida íntima com a pública, quando associa as práticas de leituras à circulação de livros, disponíveis em academias, institutos, grêmios, gabinetes, associações, bibliotecas, livrarias e escolas. Localiza a intensificação da vida literária da 
Um encontro com Hans-Georg Gadamer e com muitas mulheres

Bahia que, numa conjuntura de auge, entre 1850 e 1870, conta com o aparecimento de aproximadamente cinqüenta revistas $e$ periódicos literários e científicos. Romances, artigos de jornais, livros de memórias, poesias, escritos por mulheres - fontes vistas em sua dimensão pública, marcam a presença feminina no mundo das letras, um lugar, em geral, pensado como estritamente masculino. Nessa parte, ao apoiar-se ainda nas experiências de cultura letrada de outras mulheres, traz à baila muito das sociabilidades intelectuais. Remete, assim, a algo destacado por R. Gontijo (2005:260) sobre a existência de uma sociabilidade peculiar a esse meio, "reconhecido como polimórfico $e$ polifônico", indagando "de que modo o meio intelectual produz sua especificidade?" (251), com base em preocupações de Trebitsch (1992). Imagens emblemáticas de auto-representações como intelectuais estão nas fotografias de mulheres, em posição de leitura ou com um livro nas mãos. Essas mesmas imagens se associadas a reproduções de algumas capas de livros e de textos publicados, estimulam a pensar as sociabilidades intelectuais femininas, naquela dupla acepção referida por Sirinelli (2003): "a de rede organizacional e a de microclima" de tantas surpresas. Isso está presente, também, na segunda parte do livro (Capítulo 3 - "O fazer literário das baianas: práticas de escrita" e Capítulo 4 - "A imprensa $e$ as mulheres baianas: periodismo $e$ redes de solidariedade"). Aqui, memórias, escritos biográficos, correspondência de mulheres, preservados, em grande parte, em arquivos privados, além de produções literárias e jornais e revistas, ajudam a ampliar o cenário dessas sociabilidades intelectuais; discursos e práticas sociais de homens e mulheres sugerem a dinâmica social em que se move o processo de tomada de consciência de gênero na segunda metade do século XIX e que deixa, ainda, como marca, caminhos específicos de lutas femininas por educação e cidadania. Trata-se de uma leitura que estimula e faz pensar novas iniciativas de pesquisa em direção a áreas ainda tão encobertas da história das mulheres. 
Suely Gomes Costa

\section{Referências bibliográficas}

CHARTIER, R. À beira da falésia. A história entre certezas e inquietude. Porto Alegre, Ed. Universidade/UFRGS, 2002 [Trad.: Patrícia. C. Ramos].

Costa, Suely G. Movimentos feministas, feminismos. Estudos Feministas, vol 12 /Especial, Florianópolis, CFH/CCE/UFSC, 2004, pp.23-36.

GADAMER, Hans-Georg. Problemas Epistemológicos das Ciências Humanas. In FRUCHON, Pierre. (org.) O problema da consciência histórica. Rio de Janeiro, Editora da Fundação Getúlio Vargas, 1998.

GONTIJO, R. História, cultura, política e sociabilidade intelectual. In: SOIHET, R., BICALHO, Maria Fernanda B., GouvÊA, Maria de Fátima S. Culturas políticas: ensaios de história cultural, história política e ensino de história. Rio de Janeiro, Mauad, 2005.

Piscitelli, Adriana. Reflexões em torno do gênero e feminismo. In: CostA, Claudia Lima e ScHMIDT, Simone Pereira. (orgs.) Poéticas e políticas feministas. Florianópolis, 2004.

RAmOS, Alcides Freire; PATRIOTA, Rosangela e PESAVENTO, Sandra Jatahy. Imagens da História: objetos da História Cultural. São Paulo, Editora Hucitec, 2008.

SIRINELLI, Jean-François. Os intelectuais. In: RÉMOND, R. Por uma história política. $2^{\mathrm{a}}$ ed. Rio de Janeiro, Editora FGV, 2003 [Trad.: Dora Rocha].

TREBITSCH, Michel. Avant-propos: la chapelle, le clan et le microcosme. Les Cahiers de l'Instintut d'Histoire du Temps Présent - Sociabilités intellectuelle, $\mathrm{n}^{\circ}$ 20, Paris, Centre National de la Recherche Scientifique, mars, 1992. 